\title{
Rancang Bangun Sistem Informasi Akademik Berbasis Web pada Madrasah Aliyah Attaqwa Tangerang
}

\author{
Ahmad Yani ${ }^{1}$, Ahmad Syauki ${ }^{3}$, Siti Marlina ${ }^{3}$ \\ ${ }^{1}$ Universitas Bina Sarana Informatika \\ e-mail: ahmad.amy@bsi.ac.id \\ 2,3STMIK Nusa Mandiri \\ 2e-mail: signet_21@yahoo.com \\ 3e-mail: siti.smr@nusamandiri.ac.id
}

\begin{abstract}
Abstrak
Madrasah Aliyah Attaqwa Tangerang adalah salah satu lembaga pendidikan yang sedang berkembang di kawasan Tangerang. Perkembangan lembaga pendidikan Attaqwa ini akan sangat terbantu dengan pemanfaatan teknologi informasi. Penulis ingin berkontribusi kepada lembaga pendidikan Attaqwa ini dengan merancang Sistem Informasi Akademik berbasis web agar dapat membantu kelancaran proses kegiatan belajar mengajar. Sistem Informasi Akademik yang penulis rancangan ini menggunakan metode pengembangan sistem waterfall mulai dari tahap analisis, desain, implementasi, testing dan pemeliharaan sistem. Sistem Informasi Akademik ini akan mengelola data siswa, guru, nilai dan informasi sekolah yang akan disampaikan kepada masyarakat luar dengan lebih efektif dan memiliki ruang lingkup yang lebih luas dalam proses penyaluran informasi. Dengan adanya Sistem Informasi Akademik berbasis Web akan sangat membantu lembaga pendidikan Attaqwa dengan memberdayakan secara optimal fasilitas internet yang telah ada untuk mempermudah pengolahan data dalam pelaksanaan kegiatan operasional lembaga juga menjadikan website sebagai salah satu sarana yang efektif dan efesien dalam hal mengenalkan atau mempromosikan lembaga pendidikan Madrasah Attaqwa Tangerang kepada masyarakat.
\end{abstract}

Kata Kunci : Sistem Informasi Akademik Berbasis Web

\begin{abstract}
Madrasah Aliyah Attaqwa Tangerang is one of the developing educational institutions in the Tangerang area. The development of Attaqwa's educational institutions will be greatly helped by the use of information technology. The author wants to contribute to Attaqwa's educational institution by designing a web-based Academic Information System in order to help smooth the process of teaching and learning activities. Academic Information System which the author of this design uses the waterfall system development method starting from the stage of analysis, design, implementation, testing and system maintenance. This Academic Information System will manage student, teacher, school grades and information data that will be delivered to the outside community more effectively and have a wider scope in the process of information distribution. The existence of a Web-based Academic Information System will greatly assist Attaqwa educational institutions by optimally empowering existing internet facilities to facilitate data processing in implementing operational activities of the institution as well as making the website an effective and efficient means of introducing or promoting Madrasah educational institutions Attaqwa Tangerang to the public
\end{abstract}

Keywords: Information Systems Web-Based Academic

\section{Pendahuluan}

Pendidikan merupakan kebutuhan yang paling utama bagi kebutuhan manusia sebagai makhluk sosial, karena pendidikan sangat mempengaruhi tingkat intelektual seseorang di dalam menjalankan kehidupan bermasyarakat. Faktor pendidikan juga sangat mempengaruhi tingkat kesejahteraan 
manusia, sebagai contoh jika seseorang berpendidikan tinggi, maka peluang untuk mendapatkan pekerjaan yang dia inginkan akan semakin terbuka. Namun masih banyak faktor yang bisa mempengaruhi hal itu, dikarenakan ada juga manusia yang tidak memiliki pendidikan yang tinggi tetapi dia bisa menjadi seorang yang sukses dikarenakan keuletan dan ketekunannya dalam berusaha meningkatkan mensejahterakan hidupnya. Perkembangan dunia pendidikan bermula dari berkembangnya era komputerisasi seperti yang kita ketahui sekarang ini, dimana proses belajar mengajar sudah menggunakan berbagai macam media komputer dalam suatu lembaga pendidikan tertentu. Dengan menggunakan sistem komputerisasi maka setiap informasi yang diperlukan oleh suatu lembaga pendidikan akan mudah tersalurkan.

Menurut Saraswati (2013:1) Selama ini pengolahan data Akademik di Sekolah Menengah Pertama (SMP) Negeri 3 Pringkuku masih dilakukan secara konvensional, yaitu data diolah dengan pencatatan di buku induk. Pengolahan ini tidak mampu mencegah terjadinya pengulangan data yang dibukukan. Pengulangan data menyebabkan kurang efesien dalam pembukuan dan sering terjadi kesalahan pada hubungan data satu dengan data lainya. Masalah pengarsipan yang disimpan pada lemari akan ini mempersulit pencarian data apabila diperlukan sewaktu-waktu. Madrasah Aliyah Attaqwa merupakan Sekolah Menengah Atas yang sedang berkembang, dimana tingkat akreditasinya telah disamakan dengan Sekolah Menengah Atas (SMA) yang ada di Indonesia. Salah satu permasalahan yang dialami oleh Madrasah Aliyah Attaqwa adalah mengenai penyajian data dan informasi yang akan disampaikan masih menggunakan cara manual sehingga banyak terjadi kesalahankesalahan pada saat data itu diinput serta sempitnya ruang lingkup media informasi pada saat data dan informasi tersebut akan disampaikan kepada orang yang membutuhkannya terutama para siswa dan guru. Dengan adanya kenyataan ini menyebabkan proses belajar-mengajar di Madrasah Aliyah Attaqwa dinilai kurang efektif dan efisien. Oleh karenanya diperlukan adanya sistem informasi akademik yang berbasis komputer (web) yang mengelola data siswa, guru, nilai dan informasi sekolah yang akan disampaikan kepada masyarakat luar yang lebih efektif dan memiliki ruang lingkup yang lebih luas dalam proses penyaluran informasi. Dengan kata lain pihak penyelenggara pendidikan dalam hal ini lembaga pendidikan Attaqwa akan terbantu memudahkan pengelolaan kegiatan proses belajar mengajar. Kebutuhan proses pengolahan data akademik dan distribusi informasi baik untuk kebutuhan pengguna internal (internal user) maupun kebutuhan pengguna eksternal (external user) dengan sistem informasi yang dibangun ini akan mudah terpenuhi dengan cepat, efektif dan efisien.

\section{Metode Penelitian}

Metodologi yang digunakan dalam rancang bangun sistem informasi akademik ini adalah menggunakan pendekatan waterfall melalui tahapan berikut:

\subsection{Analisa Kebutuhan Software}

Dalam proses ini, penulis mengumpulkan dokumen-dokumen terkait yang dalam hal ini dokumen tersebut terlibat dalam proses kegiatan Akademik sekolah seperti: form data siswa, guru, jadwal pelajaran dan form penilaian siswa. Setelah itu, untuk meninjau masalah yang ada penulis memutuskan untuk mengunakan software XAMPP, Adobe Dreamweaver CS4, Adobe Photoshop, dan database MySQL sebagai software untuk membantu dalam membuat sistem yang baru.

\subsection{Desain}

Pada proses rancang atau desain ini akan menerjemahkan apa yang dibutuhkan pengguna (user) ke dalam program aplikasi yang sesuai dengan fungsi kebutuhan user, meliputi:

a. Rancangan Basis Data

Yaitu kegiatan merancang spesifikasi database yang tepat sesuai dengan yang dibutuhkan oleh sistem mulai dari jenis database yang sesuai atau memilih database yang memiliki tingkat kompatibilitas yang baik sehingga mempermudah dalam hal pemilihan bahasa pemprograman yang sesuai. Dalam hal ini kebutuhan pembuatan database penulis menggunakan software database MySQL.

b. Rancangan Fungsional Aplikasi

Rancangan fungsional pada aplikasi didasarkan pada kebutuhan pengguna (user) di dalam sistem. Hal ini dapat 
diambil dari aktivitas atau kegiatan operasional yang sedang berlangsung maka dibuatlah rancangan program aplikasi yang memiliki fungsi tertentu yang dapat memenuhi standar proses yang sudah ditentukan. Dalam hal ini aplikasi system informasi akademik berbasis web pada Madrasah Aliyah Attaqwa menggunakan model pengembangan system Unified Modelling Language (UML).

c. Rancangan Antarmuka (Interface)

Merancang bentuk tampilan yang ramah (user friendly) dan mudah dalam pemakaiannya dengan mempertimbangkan unsur estetika dalam bentuk dan design dari interface program aplikasi yang dibangun.

\subsection{Code Generation}

Bahasa pemrograman computer yang , penulis gunakan adalah bahasa pemrograman PHP, Javascript dan Jquery untuk pembuatan webnya. Hal ini dikarenakan bahasa-bahasa pemrograman tersebut merupakan bahasa pemrograman yang terpopuler dan familiar yang paling banyak di pakai untuk membuat situs atau web. Sedangkan untuk membuat databasenya penulis menggunakan bahasa Query (MySQL). Ini dilakukan karena keunggulan-keunggulan yang dimiliki database tersebut. Dalam pembuatan aplikasi berbasis web ini penulis berencana membuat web yang berorientasikan objek atau lebih dikenal dengan sebutan OOP.

\subsection{Testing}

Dalam penelitian ini, penulis melakukan pengujian program dengan metode ujicoba Blackbox. Dimana metode ini memfokuskan pada keperluan fungsional dari suatu software. Oleh sebab itu, metode ini memungkinkan pengembang software untuk membuat himpunan kondisi input yang akan melatih seluruh syarat-syarat fungsional suatu program.

Uji coba yang akan dilakukan terbagi dalam beberapa kategori yaitu:

a. Fungsi-fungsi yang salah atau hilang

b. Kesalahan interface

c. Kesalahan dalam struktur data atau akses database eksternal

d. Kesalahan performa

e. Kesalahan inisialisasi dan terminasi

\subsection{Support}

Dalam hal ini penulis menerangkan spesifikasi hardware dan software yang mampu untuk mengoperasikan web yang penulis buat. a. Umumnya, web tersebut dapat dioperasikan dengan spesifikasi hardware sebagai berikut: prossesor Intel Pentium 1.5 GHz, Ram 1 GB, harddisk $80 \mathrm{~GB}$, sedangkan perangkat yang lain dapat menyesuaikan 3 perangkat ini.

c. Web yang penulis buat dapat dioperasikan dengan spesifikasi software sebagai berikut: operasi sistem Windows $\mathrm{Xp}$ atau diatasnya, server local XAMPP, database MySQL, dan hampir semua browser terbaru dapat mengoperasikan web ini dengan stabil. Penulis juga melakukan pengecekan dan pemeliharaan secara berkala mulai dari tampilan web hingga hingga alur programnya. Sehingga web yang di gunakan dapat memilki fungsi yang optimal.

Sedangkan untuk memenuhi kebutuhan data dan informasi dalam penelitian ini, penulis menggunakan tida metode yaitu:

a. Observasi (Observation)

Dalam hal ini penulis melakukan observasi atau pengamatan secara langsung pada Madrasah Aliyah Attaqwa yang beralamat di Jl. KH Mu'min kelurahan Belendung Kecamatan Benda Kota Tangerang. Untuk mengamati kegiatan yang sedang berlangsung dan mengumpulkan data yang berkaitan dengan kegiatan akademik sekolah.

b. Wawancara (Interview)

Melakukan wawancara secara langsung dengan Kepala Sekolah yaitu Bapak Drs.Anto Supriatno dan Ust. Munasik, S.Ag selaku staff tata usaha di Madrasah Aliyah Attaqwa guna mendapatkan informasi yang ada pada institusi tersebut.

c. Studi pustaka (Literature)

Penulis melakukan penelitian kepustakaan untuk memperoleh aspekaspek teorotis dalam pengumpulan data dan informasi melalui buku referensi, jurnal ilmiah dan materi lainnya yang berhubungan dengan masalah yang di tinjau dalam penelitian ini.

\section{Hasil dan Pembahasan}

Sesuai dengan metodologi yang digunakan dalam pengembangan sistem informasi dengan pendekatan waterfaal, maka berikut ini pembahasan beberapa tahapan yang penulis lakukan.

1. Tahapan Analisis

Sistem Informasi Akademik Berbasis Web yang akan digunakan di Madrasah 
Aliyah Attaqwa ini akan memudahkan pengguna dimana para siswa dan guru tidak harus bertemu langsung di sekolah tersebut untuk berinteraksi maupun untuk mengakses informasi seputar kegiatan akademik di sekolah. Informasi mengenai akademik sekolah dapat diakses dengan hanya menggunakan media Browser. Kebutuhan pengguna (user) dalam hal ini dikategorikan menjadi dua pengguna yaitu pengguna internal (internal user) dan pengguna eksternal (external user). Masing-masing sudah barang tentu memiliki kebutuhan yang berbeda. Secara umum kebutuhan untuk pengguna internal seperti guru, staf membutuhkan sistem informasi ini untuk mengelola atau mengolah data dan informasi akademik sedangkan pengguna eksternal seperti siswa, calon siswa, orang tua siswa serta masyarakat umum membutuhkan data dan informasi hasil pengolahan data akademik. Keduanya memerlukan fasilitas antarmuka (user interface) dalam berinteraksi dengan sistem informasi dalam memenuhi kebutuhan informasnya.

b. Use Case Diagram

Use Case diagram menggambarkan kegiatan atau juga interaksi yang saling berkesinambungan (continue) antara aktor dan juga sistem.Bisa juga sebagai salah satun teknik secara umum yang digunakan, untuk mengembangkan perangkat lunak (software) atau sistem informasi, guna memperoleh kebutuhan fungsional dari sistem yang ada. Use case diagram juga digunakan untuk mendeskripsikan apa yang seharusnya dilakukan oleh sistem. Berikut ini adalah use case diagram halaman user pada Madrasah Aliyah Attaqwa Tangerang:

1) Use Case Diagram Halaman User

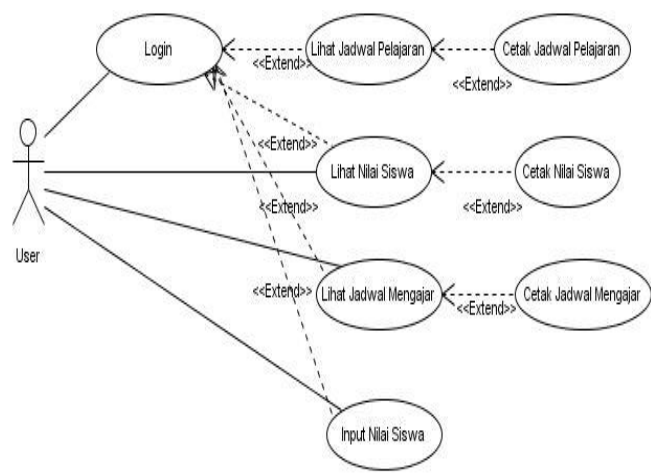

Gambar 1. Use Case Diagram Halaman User
Tabel 1. Deskripsi Use Case Diagram Halaman User:

\begin{tabular}{|c|c|}
\hline $\begin{array}{l}\text { Use } \\
\text { Case } \\
\text { Name }\end{array}$ & Pendaftaran Online \\
\hline $\begin{array}{l}\text { Require } \\
\text { ments }\end{array}$ & A1-A9 \\
\hline Goal & $\begin{array}{l}\text { Para siswa dan guru dapat mengakses } \\
\text { informasi yang dibutuhkan secara online } \\
\text { via website. }\end{array}$ \\
\hline $\begin{array}{l}\text { Pre- } \\
\text { conditio } \\
\text { ns }\end{array}$ & $\begin{array}{l}\text { Para siswa dan guru mengetahui website } \\
\text { sistem informasi akademik online }\end{array}$ \\
\hline $\begin{array}{l}\text { Post- } \\
\text { conditio } \\
\text { ns }\end{array}$ & $\begin{array}{l}\text { Para siswa dan guru mengakses } \\
\text { informasi secara online }\end{array}$ \\
\hline $\begin{array}{l}\text { Failed } \\
\text { end } \\
\text { conditio } \\
\text { n }\end{array}$ & $\begin{array}{l}\text { Para siswa dan guru membatalkan untuk } \\
\text { mengakses informasi akademik secara } \\
\text { online }\end{array}$ \\
\hline $\begin{array}{l}\text { Primary } \\
\text { Actors }\end{array}$ & Para siswa dan guru \\
\hline $\begin{array}{l}\text { Main } \\
\text { Flow/Ba } \\
\text { sic Path }\end{array}$ & $\begin{array}{l}\text { 1. Para siswa dan guru melakukan login } \\
\text { dengan menggunakan id yang telah } \\
\text { diberikan } \\
\text { 2. Para siswa melihat jadwal mata } \\
\text { pelajaran dan nilai ujian } \\
\text { 3. Para siswa mencetak jadwal mata } \\
\text { pelajaran } \\
\text { 4. Para siswa mencetak nilai yang telah } \\
\text { diinput oleh guru } \\
\text { 5. Para guru melihat jadwal mengajar } \\
\text { 6. Para guru menginput nilai siswa sesuai } \\
\text { dengan jadwal mengajar }\end{array}$ \\
\hline Invariant & - \\
\hline
\end{tabular}

2) Use Case Diagram Halamn Admin

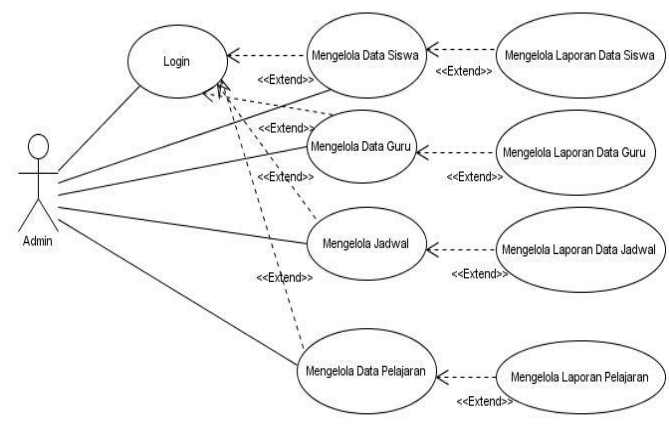

Gambar 2. Use Case Diagram Halaman User 
Tabel 2. Deskripsi Use Case Diagram Halaman User:

\begin{tabular}{|c|c|}
\hline Use Case Name & Halaman Admin \\
\hline Requirements & B1-B8 \\
\hline Goal & $\begin{array}{l}\text { Admin dapat mengelola } \\
\text { semua data sistem informasi } \\
\text { akademik online }\end{array}$ \\
\hline Pre-conditions & Admin telah login \\
\hline Post-conditions & $\begin{array}{l}\text { Admin dapat mengelola data } \\
\text { siswa, data guru, data jadwal } \\
\text { dan data mata pelajaran }\end{array}$ \\
\hline $\begin{array}{l}\text { Failed end } \\
\text { conditions }\end{array}$ & Admin gagal mengelola data \\
\hline Primary Actors & Administrator \\
\hline $\begin{array}{l}\text { Main Flow / Basic } \\
\text { Path }\end{array}$ & $\begin{array}{l}\text { 1. Admin mengelol data } \\
\text { siswa } \\
\text { 2. Admin mengelola data } \\
\text { guru } \\
\text { 3. Admin mengelola data } \\
\text { jadwal } \\
\text { 4. Admin mengelola data } \\
\text { mata pelajaran }\end{array}$ \\
\hline $\begin{array}{l}\text { Alternate Flow / } \\
\text { Invariant } 1\end{array}$ & $\begin{array}{l}\text { 1. Admin mengelola laporan } \\
\text { data siswa } \\
\text { 2. Admin mengelola laporan } \\
\text { data guru } \\
\text { 3. Admin mengelola laporan } \\
\text { data jadwal } \\
\text { 4. Admin mengelola laporan } \\
\text { data mata pelajaran }\end{array}$ \\
\hline Invariant 2 & - \\
\hline
\end{tabular}

\section{Activity Diagram}

Activity Diagram adalah diagram yang menggambarkan aliran kerja (worlflow) atau aktivitas dari sebuah sistem atau proses bisnis. Diagram aktivitas juga dapat menggambarkan alur kontrol secara umum atau secara global dari aktivitas-aktivitas atau tindakan yang terjadi dalam suatu sistem informasi.

Dalam kasus ini penulis mengusulkan beberapa aktivitas yang akan terjadi sebagai gambaran proses bisnis dalam lembaga pendidikan Madrasah Aliyah Attaqwa Tangerang. Gambaran aktivitas diagram dapat dilihat dalam gambar berikut: a. Activity Diagram Halaman User

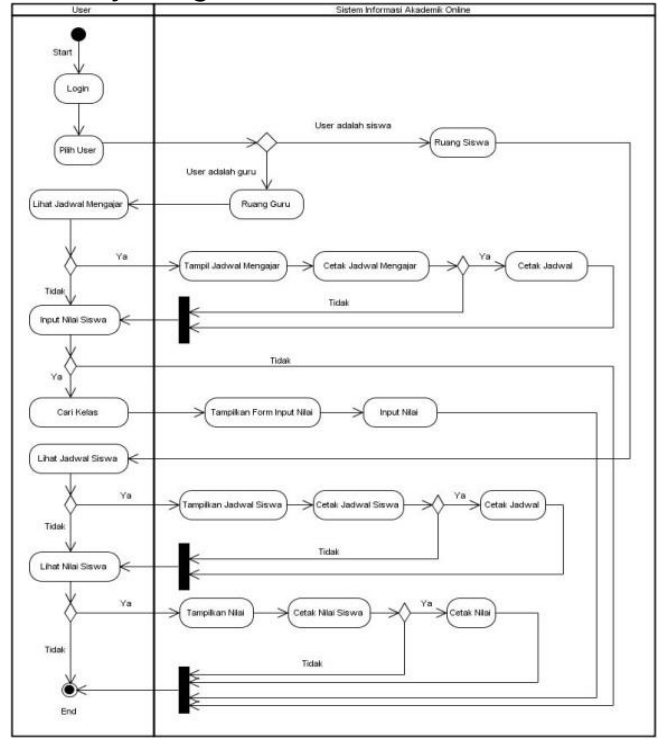

Gambar 3. Activity Diagram Halaman User

b. Activity Diagram Admin Mengelola Data Jadwal

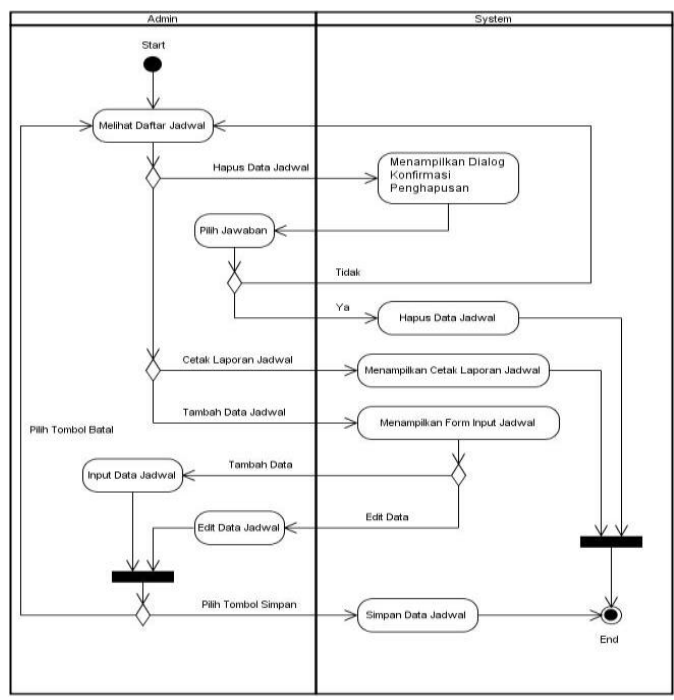

Gambar 4. Activity Diagram Admin Mengelola Data Jadwal

3 .User Interface

Di dalam web Sistem Informasi Akademi Berbasis Web Pada Madrasah Aliyah Attaqwa ini terdapat beberapa halaman yang memiliki fungsi untuk menampilkan informasi kepada pengunjung web yang membutuhkan informasi. Halaman-halaman tersebut adalah sebagai berikut : 
a. Halaman Home/Index

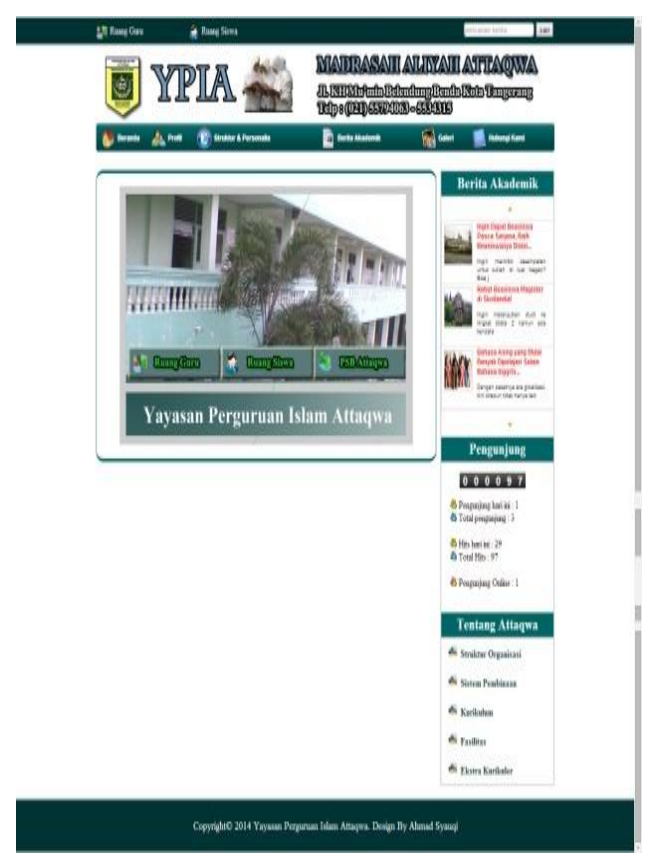

Gambar 5. User Interface Halaman Home/Index

\section{b. Halaman Beranda Siswa}

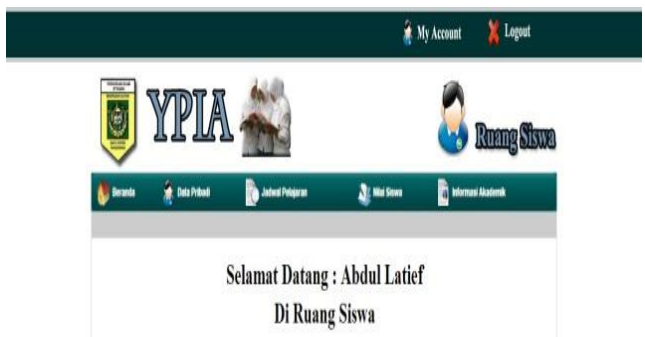

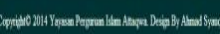

Gambar 6. User Interface Halaman Beranda Siswa c. Halaman Beranda Guru

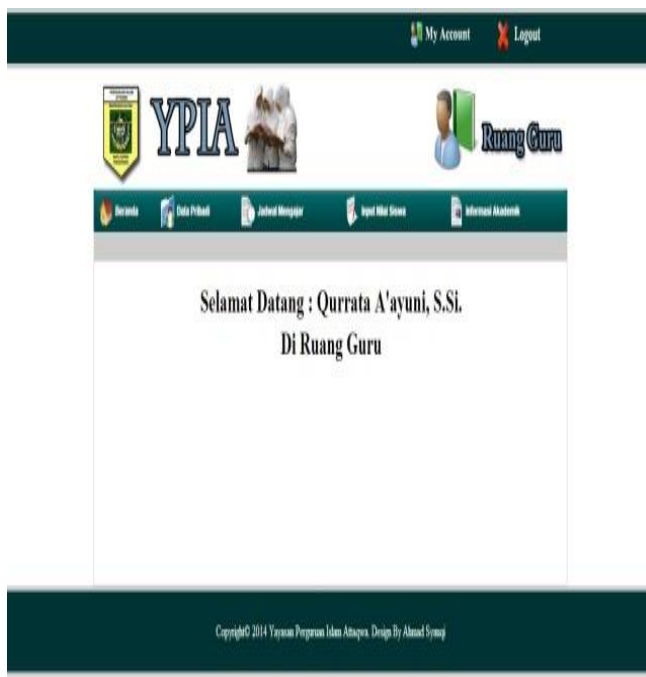

Gambar 6. User Interface Halaman Beranda Guru

\section{Kesimpulam}

Sistem informasi akademik berbasis web pada Madrasah Aliyah Attaqwa Tangerang merupakan suatu sistem komputerisasi akademik berbasis online yang bertujuan untuk memudahkan pihak sekolah dalam proses kegiatan belajar-mengajar. Sistem akademik berbasis online ini juga diharapkan akan dapat meningkatkan efektifitas dan efisiensi proses kegiatab belajar mengajar. Sistem Informasi Akademik berbasis online yang dibangun ini dapat memenuhi kebutuhan pengguna (internal atau external user) akan data dan informasi yang berkualitas (cepat,tepat dan akurat). Dengan demikian kemudahan akses terhadap data dan informasi baik yang khusus maupun yang bersifat umum akan dapat dirasakan oleh pengguna. Adapun kekurangan dari sistem ini adalah belum adanya administrator yang mampu mengoperasikan sistem ini dengan baik, karena para staf tata usaha dari pihak sekolah yang mayoritasnya adalah sarjana pendidikan, oleh karena itu perlu dilakukan sosialisasi dan pelatihan secara berkala agar sistem informasi akademik ini dapat berfungsi dengan baik sesuai dengan yang direncanakan dan diharapkan. Tidak ada istilah sempurna dalam khasanah pengembangan ilmu terutama dalam bidang penelitian. Penelitian dan pengembangan sistem informasi ini tentunya masih 
memerlukan lanjutan perbaikan dan penyempurnaan agar lebih baik lagi dalam memberikan kontribusi yang nyata di bidang penelitian.

Dari hasil kesimpulan di atas, penulis memberikan beberapa saran sebagai solusi alternatif pemikiran dengan harapan agar dari aspek ilmu pengetahuan tidak lagi bersifat monoton akan tetapi bisa lebih berkembang lagi. Untuk sistem informasi yang dibuat dapat efektif. Adapun saransaran yang dapat penulis sampaikan adalah sebagai berikut:

a. Aplikasi Sistem Informasi yang berbasis web yang telah dibuat hendaknya dapat dioperasikan dengan baik dan benar agar dapat mencapai tujuan yang diharapkan.

b. Pemakai komputer (user) harus lebih menambah dan memperkaya pengetahuan tentang hardware dan software secara seimbang agar dapat membantu kelancaran proses penerapan teknologi komputer serta memahami lebih dalam lagi tentang teknologi informasi yang berbasis internet serta teknologi client server.

c. Sebelum menetapkan teknologi informasi yang berbasis web pada suatu bidang alangkah baiknya pengelola akan lebih mudah menjalankan aplikasi serta mengerti akan proses dalam menyelesaikan masalah yang bersifat komputasi yang ada di dalam bidang tersebut.

Untuk meningkatkan kinerja serta untuk mengembangkan aplikasi ini maka sebaiknya diadakan sosialisasi dan pelatihan secara berkala terhadap para user yang akan menggunakan aplikasi ini serta melakukan pengembangan aplikasi mulai dari tampilan halaman web sampai dengan perawatan (maintenance). Sistem informasi Akademik berbasis web ini dapat terus dikembangkan sesuai dengan dinamika yang terjadi dalam organisasi dan kebutuhan pengguna yang tentunya kebutuhan akan data dan informasi terkini. Penelitian ini juga dapat dijadikan sebagai dasar penelitian untuk dapat melakukan penelitian lanjutan yang lebih konprehensif dan dapat memberikan kontribusi yang nyata dalam bidang penelitian dan bidang pendidikan.

\section{Referensi}

Anhar.(2010). Buku Panduan Menguasai PHP \& MySQL Secara Otodidak. Jakarta: Mediakita, 2010.

Enterprise, Jubilee.(2009). Photoshop 3 in 1. Jakarta: PT. Elex Media Komputindo.

Fatta, Hanif Al(2007). Analisa Perancangan Sistem Informasi untuk Keunggulan Bersaing Perusahaan dan Organisasi Modern. Yogyakarta: CV. Andi Offset (Penerbit Andi).

Komputer, Wahana.(20100. Shortcourse Mendesain Website Dinamis dan Menarik dengan Adobe Dreamweaver CS 4. Yogyakarta: CV. Andi Offset.

Puspita, Heni A,(2010). Membangun Website Interaktif Dengan Adobe Creative Suite5 Tingkat Dasar. Jakarta: Scripta.

Riyadi, Septima, Anggiani, Eko Retnandi, Asep Dedd.(2012). Perancangan Sistem Informasi Berbasis Website Subsistem Guru Di Sekolah Pesantren Persatuan Islam 99 Rancabango. ISSN : 2302-7339. Jurnal STT-Garut, Vol. 09 No. 40,1-7.

Saraswati, Ella.(2013). Sistem Informasi Akademik Berbasis Web Pada Sekolah Menengah Pertama Negeri Peringkuku. ISSN: 2302-5700: IJNS, Volume 2 No 4, 9-17.

Sutanta, Edhy.(2011). Basis Data dalam Tinjauan Konseptual. Yogyakarta: CV. Andy Offset.

Utama, Yadi.(2011). Sistem Informasi Berbasis Web Jurusan Sistem Informasi Fakultas IImu Komputer Universitas Sriwijaya. ISSN:2085-1588. Jurnal Sistem Informasi (JSI), VOL. 3, NO. 2, Oktober, 2011,359-370. 